\title{
Efecto de la infección por el virus de la rabia sobre la expresión de parvoalbúmina, calbindina y calretinina en la corteza cerebral de ratones
}

\author{
Orlando Torres-Fernández ${ }^{1}$, Gloria E. Yepes ${ }^{1}$, \\ Javier E. Gómez ${ }^{2}$, Hernán J. Pimienta ${ }^{3}$ \\ 1 Laboratorio de Microscopía, Instituto Nacional de Salud, Bogotá, D.C., Colombia. \\ 2 Bioterio, Instituto Nacional de Salud, Bogotá, D.C., Colombia. \\ ${ }^{3}$ Centro de Estudios Cerebrales, Facultad de Salud, Universidad del Valle, Cali, Colombia.
}

Algunas manifestaciones clínicas de la rabia, así como los resultados de experimentos con cultivos celulares y animales de laboratorio han llevado a sugerir que el virus de la rabia afecta la neurotransmisión gabaérgica. En la corteza cerebral existen diferentes tipos de neuronas que sintetizan el neurotransmisor GABA. Éstas se pueden identificar con marcadores neuronales, entre los que se destacan tres proteínas ligadoras de calcio: la parvoalbúmina $(P V)$, la calbindina $(C B)$ y la calretinina $(C R)$. El virus de la rabia se disemina a través de la corteza cerebral pero se desconocen sus posibles efectos citopáticos sobre las neuronas gabaérgicas. Para evaluar el efecto de la rabia sobre estas neuronas, se estudió mediante inmunohistoquímica la expresión de PV, CB y CR en la corteza frontal de ratones normales y ratones infectados con virus 'calle' o virus 'fijo' de la rabia. La PV se expresó en neuronas multipolares dispersas regularmente entre las capas II y VI, y en botones sinápticos que bordeaban el soma de las neuronas piramidales. La inmunorreactividad a CB se manifestó en dos franjas corticales: la primera, en las capas supragranulares II y III en neuronas con somas redondeados e inmersos en un neuropilo intensamente marcado; la segunda, en las capas infragranulares $\mathrm{V}$ y $\mathrm{VI}$ en neuronas multipolares dispersas y rodeadas por un neuropilo menos reactivo. La CR se expresó en neuronas bipolares con somas fusiformes distribuidas en las seis capas corticales, pero concentradas principalmente en las capas II y III. Hubo una característica común en las muestras infectadas con los dos tipos de virus: la inmunotinción a PV fue más intensa que en las muestras normales. La infección derivada del virus 'calle' no causó alteraciones adicionales en la expresión de las tres proteínas. En contraste, la infección con virus 'fijo' produjo una reducción notable del número de neuronas $\mathrm{CB}_{+}$, así como de la inmunorreactividad a CB en el neuropilo de la corteza frontal. Además, provocó una disminución significativa del tamaño de las neuronas $\mathrm{CR}+$ en la corteza del cíngulo. Estos resultados aportan evidencia histológica en apoyo de la hipótesis según la cual las neuronas gabaérgicas son afectadas por el virus de la rabia.

Palabras clave: rabia, parvoalbúmina, calbindina, calretinina, GABA.

Effect of rabies virus infection on the expression of parvalbumin, calbindin and calretinin in mouse cerebral cortex

Some clinical features of rabies and experimental evidence from cell culture and laboratory animals suggest impairment of gabaergic neurotransmission. Several types of gabaergic neurons occur in the cerebral cortex. They can be identified by three neuronal markers: the calcium binding proteins (CaBPs) parvalbumin (PV), calbindin (CB) and calretinin (CR). Rabies virus spreads throughout the cerebral cortex; however, rabies cytopathic effects on gabaergic neurons are unknown. The expression of calcium-binding proteins (CaBPs) parvalbumin (PV), calbindin (CB) and calretinin (CR) was studied in the frontal cortex of mice. The effect of gabaergic neurons was evaluated immunohistochemically. The distribution patterns of CaBPs in normal mice and in mice infected with 'fixed' or 'street' rabies virus were compared. PV was found in multipolar neurons located in all cortical layers except layer I, and in pericellular clusters of 
terminal knobs surrounding the soma of pyramidal neurons. CB-immunoreactivity was distributed in two cortical bands. One was composed of round neurons enclosed by a heavily labeled neuropil; this band corresponds to supragranular layers II and III. The other was a weakly stained band of neuropil which contained scattered multipolar CB-ir neurons; this corresponds to infragranular layers V and VI. The CR-ir neurons were bipolar fusiform cells located in all layers of cortex, but concentrated in layers II and III. A feature common to samples infected with both types of viruses was a more intense immunoreactivity to PV in contrast to normal samples. The infection with 'street' virus did not cause additional changes in the expression of CaBPs. However, the infection with 'fixed' virus produced a remarkable reduction of CB-immunoreactivity demonstrated by the loss of CB-ir neurons and low neuropil stain in the frontal cortex. In addition, the size of CR-ir neurons in the cingulate cortex was decreased.

Key words: rabies, parvalbumin, calbindin, calretinin, GABA

En la corteza cerebral existen dos poblaciones neuronales: las neuronas piramidales y las interneuronas. Las primeras representan el $70 \%$ del total de las neuronas corticales; sus axones pueden emerger desde la sustancia gris cortical y llegar a sitios distantes en el hemisferio contralateral, el tallo cerebral o, inclusive, a la médula espina (1-3). Las células piramidales contienen glutamato, el más importante neurotransmisor excitatorio del sistema nervioso central $(2,3)$. Las interneuronas pueden alcanzar el $30 \%$ de la población neuronal en la corteza y se conocen también como células de axón corto puesto que sus axones no salen de la sustancia gris; su blanco principal son las neuronas piramidales vecinas $(1,3-5)$. Las neuronas de axón corto contienen ácido $\gamma$-amino- $n$-butírico (GABA), el principal neurotransmisor inhibitorio del sistema nervioso $(1,3,4)$. Así, las interneuronas, a través del GABA, regulan la actividad excitatoria de las neuronas piramidales; si se rompe el equilibrio de esta interacción, se afecta la función neurológica $(3,6)$. Las alteraciones del sistema gabaérgico pueden provocar alteraciones motoras y emocionales $(6,7)$. El cuadro clínico de la rabia, aunque puede variar individualmente, reúne algunas características que sugieren efectos sobre el sistema gabaérgico: mioclonía, agitación, confusión, alteraciones emocionales, convulsiones generalizadas, comportamiento agresivo y

\section{Correspondencia:}

Orlando Torres-Fernández

Laboratorio de Microscopía, Instituto Nacional de Salud,

Av. Calle 26 No. 51-60, Of: 233, Tel: 571-2207700 ext. 453,

E-mail: otorresf@hemagogus.ins.gov.co

Recibido: 22/08/03; aceptado: 25/02/04 fases alternas de hiperexcitación y relajación (812). La posible participación de este sistema neurotransmisor en la patogénesis de la rabia ha sido sugerida por algunos investigadores (12). Además, en experimentos de laboratorio se ha confirmado el efecto de la rabia sobre el metabolismo del GABA $(12,13)$. Esta evidencia preliminar sobre la relación entre la rabia y el GABA motiva a la exploración en detalle del efecto de la infección sobre los diferentes tipos de neuronas que sintetizan este neurotransmisor. Por otra parte, en el cerebro afectado por rabia, la histopatología convencional no revela cambios neuronales distintos a las inclusiones citoplasmáticas conocidas como cuerpos de Negri, el rasgo patognomónico de la rabia en estado natural $(9,10,14-16)$; por tanto, se requiere aplicar métodos diferentes para el estudio histológico que aporten nueva información sobre la patogénesis de esta enfermedad.

Una alternativa para estudiar las neuronas gabaérgicas de la corteza cerebral es la evaluación de la expresión de las proteínas ligadoras de calcio ( $\mathrm{CaBP}$, calcium binding protein). Las CaBP - parvoalbúmina (PV), calbindina (CB) y calretinina (CR) - han sido de gran utilidad en neurociencias por su papel como marcadores neuronales (17-20). En la corteza cerebral, las CaBP se expresan selectivamente en los diferentes tipos de interneuronas $(4,19,20)$; su alta solubilidad les permite estar presentes en todo el citosol, aun en las dendritas distales y en los axones, inclusive en los botones sinápticos (17). Estas características son ideales para estudiar la morfología celular, la integración sináptica y la distribución de poblaciones 
neuronales dentro del sistema nervioso. La hipótesis más aceptada sobre su función es que contribuyen en la regulación de la concentración del calcio intracelular para lo cual poseen cadenas laterales hidrofílicas que se unen a iones calcio $(17,18)$. En la última década se han adelantado estudios inmunohistoquímicos sobre la expresión de las CaBP en neuropatologías como la enfermedad de Creutzfeldt-Jakob (21), la esquizofrenia (22), la epilepsia (23), la encefalitis por sida (24) y la enfermedad de Alzheimer $(25,26)$. Sin embargo, no se conocen estudios similares en encefalitis causadas por virus neurotrópicos.

El propósito de este trabajo fue estudiar el efecto de la infección por el virus de la rabia sobre las subpoblaciones de neuronas gabaérgicas corticales, por medio de la evaluación inmunohistoquímica de la expresión de CB, CR y PV en la corteza frontal motora del ratón.

\section{Materiales y métodos}

Manejo de los animales e

inoculación del virus de la rabia

Se utilizaron ratones ICR hembras, en su mayoría de 4 a 6 semanas y un segundo grupo de 6 a 8 semanas, confinados en el bioterio del Instituto Nacional de Salud (INS), siguiendo las normas éticas y legales exigidas para la investigación con animales de laboratorio. El material infectado con rabia se obtuvo a partir del cerebro de un perro procedente de la Costa Atlántica colombiana, caracterizado dentro de la variante genética colombiana II (27). Una muestra de este material se inoculó por vía intracerebral a ratones lactantes para obtener mayor cantidad de tejido infectado. De estos animales se extrajeron los cerebros, se maceraron y se tomaron muestras para depositarlas en viales de $0,5 \mathrm{ml}$ y guardarlas en un congelador $\mathrm{a}-70^{\circ} \mathrm{C}$.

Para llevar a cabo las inoculaciones, en cada caso se tomó el contenido de uno de los viales y se obtuvo una dilución al $10 \%$ en agua destilada a la que se le adicionó suero equino normal al $2 \%$ y antibióticos (200 Ul/ml de penicilina y $4 \mathrm{mg} / \mathrm{ml}$ de estreptomicina). Cada animal se inoculó por vía intramuscular en la extremidad posterior derecha con una cantidad de 0,03 $\mathrm{ml}$ de la dilución. En total se inocularon 10 ratones por este procedimiento. Un segundo grupo de 10 animales se inoculó por vía intracerebral con $0,03 \mathrm{ml}$ de la misma dilución. Puesto que el virus inoculado con este material provenía de un animal infectado en condiciones naturales, se denomina virus silvestre o virus 'calle'. Un tercer grupo de 10 animales se inoculó por vía intramuscular con 0,03 $\mathrm{ml}$ de una solución similar a las anteriores, pero con un virus adaptado en el laboratorio, también conocido como virus 'fijo', de la cepa CVS (challenge virus standard). Para todos los procedimientos, se utilizó un animal control, sin inocular, por cada animal infectado. Los ratones enfermos se sacrificaron cuando alcanzaron el estado de postración (moribundos). Simultáneamente, se sacrificaron también los controles. Previamente, los animales se anestesiaron inyectándoles ketamina al $5 \%(0,08 \mathrm{ml})$ y xilazina al $2 \%(0,01$ $\mathrm{ml}$ ) por vía intramuscular. Luego, se realizó la fijación por perfusión intracardiaca, inicialmente con $50 \mathrm{ml}$ de tampón fosfato salino (PBS) a pH 7,3 e inmediatamente después con paraformaldehído al $4 \%$. Posteriormente, se procedió a extraer los cerebros completos para colocarlos en paraformaldehído al $4 \%$ y dejarlos en nevera a $4^{\circ} \mathrm{C}$ hasta el día en que se procesaron para el estudio histológico.

\section{Inmunohistoquímica}

Las reacciones inmunohistoquímicas se llevaron a cabo en cortes coronales de 50-100 $\mu \mathrm{m}$ de espesor obtenidos con un Vibratome ${ }^{\circledR} 1000$ Plus. El área seleccionada comprendió la corteza frontal, dorsal al cuerpo calloso (figura 1). Para delimitar la zona de estudio y ubicar las neuronas inmunorreactivas dentro de las capas corticales, se tomó como guía el atlas de cerebro de ratón publicado por Valverde (28). Cada secuencia de 4 cortes seriados del material fijado en paraformaldehído se destinó para la inmunodetección de $\mathrm{CB}, \mathrm{CR}, \mathrm{PV}$ y rabia. El diagnóstico inmunohistoquímico de rabia se realizó siguiendo el procedimiento previamente estandarizado para material incluido en parafina (29) adaptado a cortes de vibrátomo.

Los cortes de vibrátomo se procesaron haciéndolos flotar en las soluciones empleadas en cada una 
de las etapas del protocolo, en agitación constante y a temperatura ambiente $\left(20^{\circ} \mathrm{C}\right)$. Inicialmente, los cortes se dejaron durante varias horas o toda la noche en PBS (pH 7,3). Luego, se trataron con $\mathrm{H}_{2} \mathrm{O}_{2}$ al $3 \%$ por $10-30$ minutos en PBS para bloquear la peroxidasa endógena. Después de lavarlos en PBS, los cortes se preincubaron durante 30-60 minutos en PBS con albúmina de suero bovino (BSA) al $3 \%$ y suero normal al $3 \%$. A continuación se retiró la solución anterior y los cortes se incubaron toda la noche en los anticuerpos primarios: anti-CB (Sigma monoclonal, 1:2.500); anti-PV (Sigma monoclonal, $1: 5.000$ ) y anti-CR (Chemicon policlonal, 1:2.500). Al día siguiente se continuó con la incubación en anticuerpo secundario biotinilado anti-ratón $\lg G$ (Sigma 1:600) para CB y PV y anti-conejo IgG (Sigma 1:400) para CR durante 2 horas y, luego, en solución $A B C$ (Vectastain) por 2 horas. Para el revelado, se utilizó diaminobenzidina (DAB/ICN) al $10 \%$ o un estuche DAB-níquel (Vectastain). Finalmente, los cortes se deshidrataron y se montaron con citorresina.

\section{Análisis cuantitativo}

Para cada uno de los tipos de inoculación viral (intracerebral con virus 'calle', intramuscular con virus 'calle' e intramuscular con virus 'fijo') se seleccionaron 5-7 casos (unidades experimentales), con sus respectivos controles, para contar el número de células que expresaron cada uno de los marcadores. En cada unidad experimental se seleccionaron 5 cortes (repeticiones) para realizar los conteos celulares en la corteza cerebral. El área de conteo correspondió a una columna de 1 $\mathrm{mm}$ de ancho de la corteza frontal, a nivel del cuerpo calloso (figura 1). En esta zona, la altura de la corteza deshidratada se aproxima también a $1 \mathrm{~mm}$; por tanto, el área de conteo en cada repetición fue de $1 \mathrm{~mm}^{2}$, aproximadamente. El método de contar células en columnas de una anchura determinada, que incluyan todo el espesor de la corteza, es recomendado por otros autores pues minimiza el efecto de la deshidratación que hace parte del procesamiento histológico de la muestra (26). Se realizaron conteos de las neuronas marcadas en un microscopio Zeiss dotado con un micrómetro de malla Netzmiier de $1 \mathrm{~mm}^{2}$ y conteos semiautomáticos en un foto- microscopio Axiophot Zeiss con ayuda del programa de análisis de imágenes KS-300.

La comparación entre los grupos control con cada uno de los grupos problema se analizó con una prueba estadística no paramétrica (prueba de rangos de Wilcoxon-Mann-Whitney de dos colas), aplicando una fórmula y una tabla diseñadas para trabajar con muestras pequeñas (30). Un procedimiento similar se siguió para la descripción cuantitativa del tamaño de los perfiles neuronales inmunorreactivos para cada una de las CaBP. Se seleccionaron 5 casos (unidades experimentales) correspondientes a cada uno de los dos tipos de inoculación periférica (intramuscular con virus 'calle' e intramuscular con virus 'fijo') con sus respectivos controles, para medir el tamaño promedio (área en $\mathrm{mm}^{2}$ ) de los perfiles neuronales que expresaron cada uno de los marcadores. En cada unidad experimental se seleccionaron 20 células (repeticiones) para medir su diámetro y su área con ayuda del programa de análisis de imágenes Zeiss KS-300. En lo posible, se escogieron perfiles neuronales en los que se podían observar el núcleo y el nucléolo. El análisis estadístico se realizó mediante el método antes mencionado.

\section{Resultados}

\section{La infección con los diferentes virus y tipos de inoculación de la rabia}

La inoculación intracerebral con virus 'calle' y la inoculación intramuscular con virus 'fijo' provocaron una mortalidad del $100 \%$ y en menor tiempo ( 8 a 12 días), que la inoculación intramuscular con virus 'calle', en donde la mortalidad alcanzó un $70 \%$ en un período de 15 a 25 días. No se observaron diferencias macroscópicas importantes al comparar los cerebros de animales infectados con sus respectivos controles, aunque en algunos cerebros afectados por virus 'fijo' se presentó congestión en los vasos de las meninges. El diagnóstico inmunohistoquímico de la rabia se realizó mediante la observación de los cuerpos de Negri en todos los animales inoculados con virus 'calle'. Estas inclusiones citoplasmáticas fueron abundantes y diseminadas en la corteza frontal de los cerebros inoculados con virus 'calle' por vía intracerebral. Los cuerpos de Negri se 


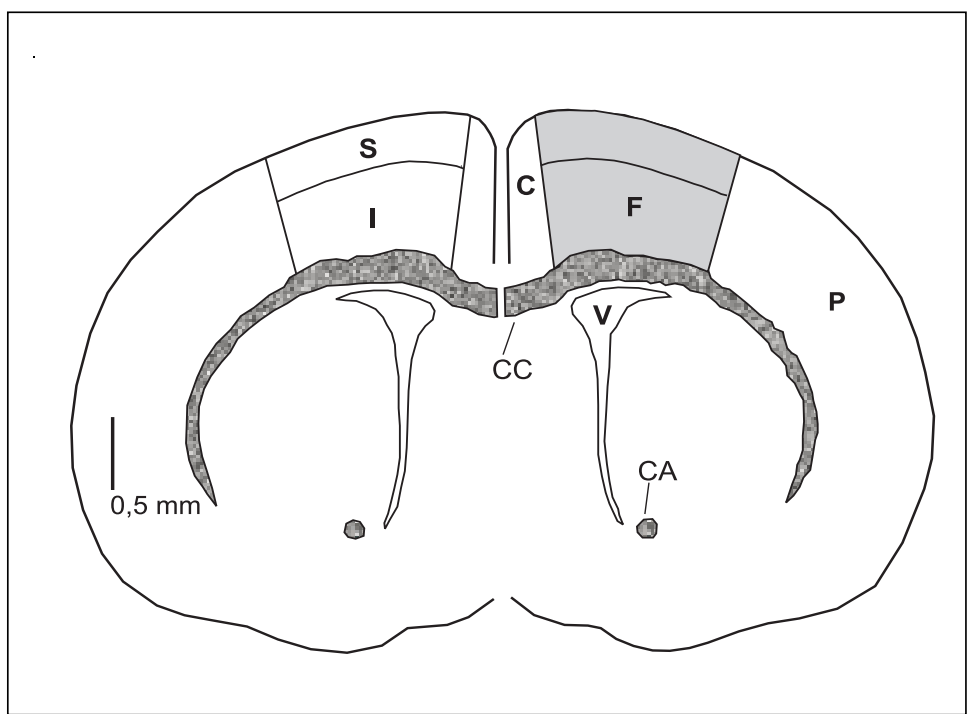

Figura 1. Esquema de un corte coronal del cerebro de ratón a nivel del cuerpo calloso (CC). El área sombreada corresponde a la corteza frontal motora primaria $(F)$. Capa supragranular $(\mathrm{S})$, capa infragranular (I), corteza del cíngulo $(C)$, corteza parietal $(P)$, ventrículo lateral $(V)$, comisura anterior $(C A)$.

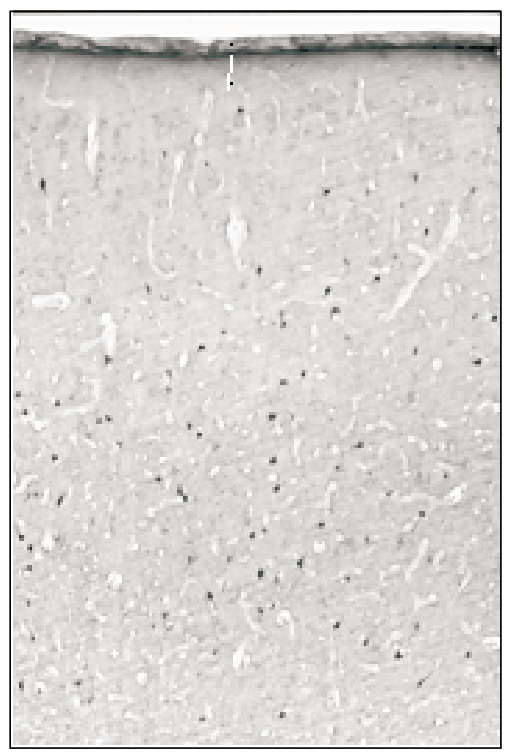

Figura 2. Distribución de neuronas $\mathrm{PV}+$ en la corteza frontal del ratón. 100X. $(\uparrow)$, piamadre. hallaron en menor proporción en el material inoculado con el mismo virus por vía intramuscular, en donde se localizaron principalmente en las neuronas piramidales de la capa cinco. En los cerebros de los animales inoculados con virus 'fijo', apenas se pudieron detectar pequeñas inclusiones citoplasmáticas inmunorreactivas a la rabia sin las características de los cuerpos de Negri. Sin embargo, hubo alta concentración de antígeno viral en las células piramidales que demarcó muy bien la morfología del soma y la dendrita apical.

\section{Expresión y distribución de parvoalbúmina}

Las neuronas inmunorreactivas a PV se hallaron dispersas regularmente desde la capa II hasta la capa VI de la corteza frontal (figura 2), tanto en el material control como en el infectado. Hubo diversidad de formas y tamaños pero la mayoría eran células multipolares con somas redondeados. En los controles, su diámetro promedio mínimo fue de $11,5 \mu \mathrm{m}$ y máximo de $15,9 \mu \mathrm{m}(\mathrm{n}=200)$. En el cuadro 1 se relacionan los datos correspondientes al número de neuronas $\mathrm{PV}+$ en $1 \mathrm{~mm}$ de corteza frontal y al tamaño de los perfiles de los somas neuronales inmunorreactivos para los diferentes grupos de estudio. No hubo diferencia estadísticamente significativa en el número de células marcadas en los controles comparado con el material de cada uno de los tipos de inoculación. Tampoco se halló diferencia significativa en el tamaño de las neuronas PV+ al comparar las correspondientes al material inoculado con virus 'calle' y virus 'fijo' con sus controles.

Es importante destacar que el virus de la rabia, inoculado por cualquiera de las tres formas ya mencionadas, acentuó la inmunotinción con PV. En el material infectado se observaron más intensamente coloreadas las neuronas y sus procesos celulares, así como los botones sinápticos y las fibras inmunorreactivas del neuropilo. Se observó que no hay efecto de la infección sobre la cantidad de conexiones sinápticas perisomáticas de las neuronas piramidales. Esto se dedujo al observar los anillos formados por botones sinápticos PV+ (figura 3), los cuales están formados por las terminaciones axonales de las células en cesta que rodean al pericarion de las células piramidales. También se hallaron, en algunos cortes, pequeñas barras verticales inmunorreactivas a PV y que se sabe corresponden a terminaciones axonales provenientes de las neuronas axo-axónicas o células en candelabro (figura 4). Éstas se 
Cuadro 1. Expresión de parvoalbúmina (PV) en neuronas de la corteza frontal de ratones infectados con rabia mediante diferentes tipos de inoculación y sus respectivos controles.

\begin{tabular}{|c|c|c|}
\hline Tipo de inoculación & $\begin{array}{l}\text { No. promedio de neuronas } \\
\text { PV+ en } 1 \mathrm{~mm} \text { de corteza } \\
(\mathrm{n}=7)\end{array}$ & $\begin{array}{l}\text { Tamaño del soma } \\
\text { Área promedio en } \mu \mathrm{m}^{2} \\
(n=5)\end{array}$ \\
\hline $\begin{array}{l}\text { Virus 'calle' intracerebral } \\
\text { Controles }\end{array}$ & $\begin{array}{l}121 \pm 5 \\
119 \pm 7 \\
p=0,310\end{array}$ & \\
\hline $\begin{array}{l}\text { Virus 'calle' intramuscular } \\
\text { Controles }\end{array}$ & $\begin{array}{l}122 \pm 21 \\
123 \pm 8 \\
p=0,228\end{array}$ & $\begin{array}{l}129 \pm 18 \\
132 \pm 11 \\
p=0,345\end{array}$ \\
\hline $\begin{array}{l}\text { Virus 'fijo' intramuscular } \\
\text { Controles }\end{array}$ & $\begin{array}{l}121 \pm 18 \\
119 \pm 8 \\
p=0,310\end{array}$ & $\begin{array}{l}136 \pm 16 \\
132 \pm 11 \\
p=0,345\end{array}$ \\
\hline
\end{tabular}

* Unidades experimentales compuestas por 20 células cada una (repeticiones). Por tanto, cada dato corresponde al promedio de la medición de 100 somas.

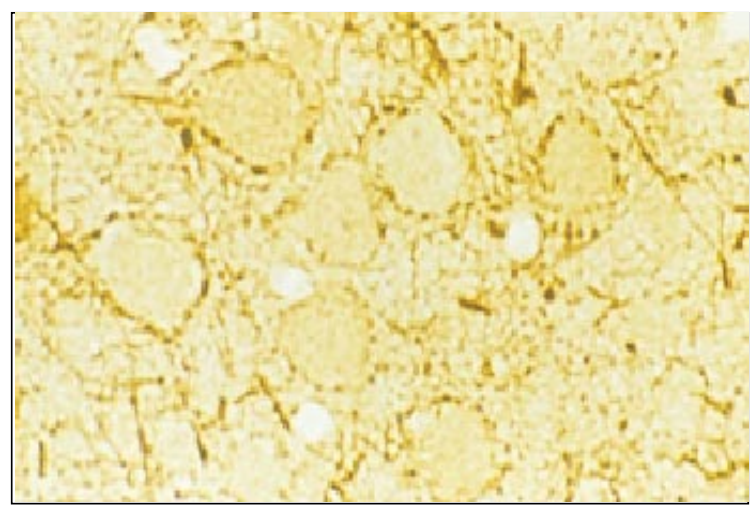

Figura 3. Anillos formados por botones sinápticos PV+ originados en las células en cesta y que hacen contacto con el soma de las neuronas piramidales. 800X.

observaron con mayor facilidad y en mayor cantidad en el material infectado.

\section{Expresión y distribución de calbindina}

En la corteza frontal del ratón se distinguieron, por su localización, dos poblaciones neuronales inmunorreactivas para $C B$ : una de ellas conformada por cuerpos celulares redondeados 0 ligeramente ovalados, concentrados hacia las capas supragranulares (capas II y III), y la otra constituida por células multipolares dispersas en las capas infragranulares (capas $\mathrm{V}$ y VI). En la capa I no se hallaron somas pero sí fibras inmunorreactivas. En la franja supragranular, además de la mayor densidad de interneuronas

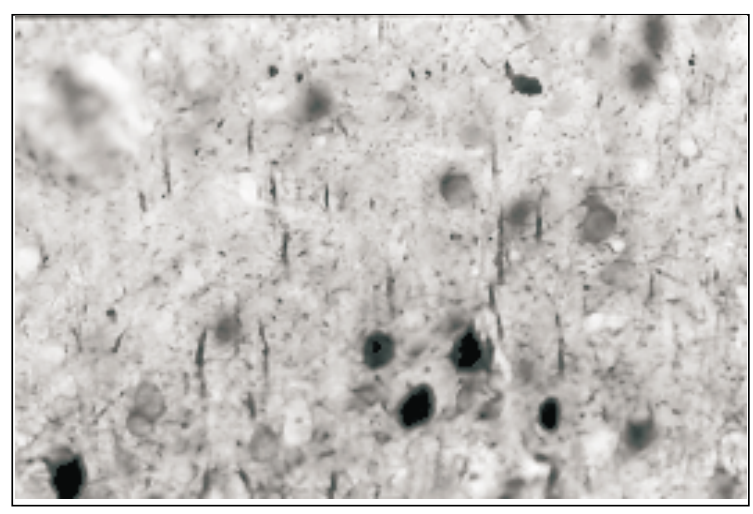

Figura 4. Terminales axónicas de las células en candelabro $\mathrm{PV}_{+}$, formadas por cadenas de botones sinápticos $(\mathrm{V})$ que conectan con el segmento inicial del axón de neuronas piramidales. 500X.

$\mathrm{CB}+$, se observó inmunotinción acentuada en el neuropilo, debido a la marcación de numerosos procesos celulares y botones sinápticos. Por esta razón, en una imagen de la corteza es notoria una banda inmunorreactiva oscura en las capas II y III, a diferencia de las capas inferiores menos coloreadas (figura 5 a y c). En la zona supragranular, además de las interneuronas $\mathrm{CB}_{+}$, también se observaron algunos perfiles de neuronas piramidales inmunorreactivas a $\mathrm{CB}$ pero con poca intensidad de coloración.

En el material control, el diámetro promedio mínimo de los somas supragranulares $\mathrm{CB}+$, fue de $11,4 \mu \mathrm{m}$ y el máximo de $15,1 \mu \mathrm{m} \quad(\mathrm{n}=200)$. En 
Cuadro 2. Número promedio de neuronas que expresaron calbindina $(\mathrm{CB})$ en una columna de $1 \mathrm{~mm}$ de corteza frontal en ratones infectados con rabia mediante diferentes tipos de inoculación y sus respectivos controles.

\begin{tabular}{|c|c|c|c|}
\hline \multirow[b]{2}{*}{ Tipo de inoculación } & \multicolumn{3}{|c|}{ No. promedio de neuronas $\mathrm{CB}+$ en $1 \mathrm{~mm}$ de corteza } \\
\hline & $\begin{array}{l}\text { Supragranulares } \\
\text { (capas II y II) }\end{array}$ & $\begin{array}{l}\text { Infragranulares } \\
\text { (capas V y VI) }\end{array}$ & Total \\
\hline Virus 'calle' intracerebral & $188 \pm 16$ & $41 \pm 6$ & $229 \pm 20$ \\
\hline Controles & $192 \pm 12$ & $39 \pm 9$ & $230 \pm 20$ \\
\hline$(n=7)$ & $p=0,227$ & $p=0,100$ & $p=0,410$ \\
\hline Virus 'calle' intramuscular & $188 \pm 16$ & $39 \pm 13$ & $227 \pm 28$ \\
\hline Controles & $186 \pm 14$ & $43 \pm 9$ & $229 \pm 20$ \\
\hline$(n=7)$ & $p=0,310$ & $p=0,120$ & $p=0,310$ \\
\hline Virus 'fijo' intramuscular & $117 \pm 37$ & $14 \pm 9$ & $131 \pm 44$ \\
\hline Controles & $187 \pm 16$ & $43 \pm 10$ & $230 \pm 24$ \\
\hline Experimento $1(\mathrm{n}=5)$ & $p=0,004^{* *}$ & $p=0,004$ ** & $p=0,004$ ** \\
\hline Virus 'fijo' intramuscular & $152 \pm 36$ & $26 \pm 11$ & $178 \pm 45$ \\
\hline Controles & $255 \pm 24$ & $62 \pm 5$ & $317 \pm 25$ \\
\hline Experimento $2(n=5)$ & $p=0,004$ ** & $p=0,004$ ** & $p=0,004$ ** \\
\hline
\end{tabular}

** Estadísticamente significativo

las interneuronas infragranulares $\mathrm{CB}+$, el diámetro promedio mínimo fue de $11,2 \mu \mathrm{m}$ y el máximo de $16,6 \mu \mathrm{m}(\mathrm{n}=200)$. En los cuadros 2 y 3 se resumen los resultados correspondientes al número de neuronas inmunorreactivas en una columna de 1 $\mathrm{mm}$ de corteza frontal y a los tamaños de los perfiles somáticos $\mathrm{CB}+$ en los diferentes grupos objeto de estudio. Al comparar el número de neuronas que expresaron $\mathrm{CB}$, no se halló diferencia estadísticamente significativa entre los controles y el material infectado con virus 'calle', inoculado ya sea por vía intracerebral o por vía intramuscular. De igual manera, no hubo diferencia significativa al analizar por separado las poblaciones de neuronas supragranulares e infragranulares $\mathrm{CB}+$ en material infectado con sus respectivos controles, tanto para la inoculación intracerebral como para la intramuscular con virus 'calle'. Tampoco se observó efecto de la infección con virus 'calle' sobre el tamaño de los perfiles neuronales $\mathrm{CB}+$ en la capa supragranular ni en la infragranular.

A diferencia del virus 'calle', la infección con virus 'fijo' provocó una fuerte disminución en la inmunorreactividad a la calbindina. En una vista panorámica es evidente la pérdida de inmunotinción $\mathrm{CB}+$ en la corteza cerebral (figura 5 b y d). Esto se manifestó en pérdida estadísticamente
Cuadro 3. Tamaño (área) de los perfiles somáticos neuronales inmunorreactivos para calbindina (CB) en la corteza frontal de ratones inoculados con rabia y sus controles.

Tamaño de neuronas CB+ en la corteza Área del soma en $\mu \mathrm{m}^{2}$

\begin{tabular}{|c|}
\hline $\begin{array}{l}\text { po de } \\
\text { oculación }\end{array}$ \\
\hline
\end{tabular}

\begin{tabular}{lcc}
\hline $\begin{array}{l}\text { Virus 'calle' } \\
\text { intramuscular }\end{array}$ & $121 \pm 8$ & $128 \pm 19$ \\
$\begin{array}{l}\text { Controles } \\
(\mathrm{n}=5){ }^{*}\end{array}$ & $124 \pm 9$ & $134 \pm 15$ \\
$\begin{array}{l}\text { Virus 'fijo' } \\
\text { intramuscular }\end{array}$ & $105 \pm 11$ & $p=0,420$ \\
$\begin{array}{c}\text { Controles } \\
(\mathrm{n}=5)^{*}\end{array}$ & $123 \pm 9$ & $99 \pm 12$ \\
\hline
\end{tabular}

* Unidades experimentales compuestas por 20 células cada una (repeticiones).

Por tanto, cada dato corresponde al promedio de la medición de 100 somas.

** Estadísticamente significativo

significativa del número de perfiles neuronales contados en 1 milímetro de corteza frontal $(p=0,004)$, tanto en la franja supragranular como en la infragranular (cuadro 2). Igualmente, el tamaño promedio de los perfiles neuronales $\mathrm{CB}+$ disminuyó en forma significativa en las dos capas $(p=0,008)$ (cuadro 3). El efecto sobre la morfología 
Cuadro 4. Número promedio de neuronas que expresaron calretinina (CR), en $1 \mathrm{~mm}$ de corteza frontal y $1 \mathrm{~mm}$ de corteza del cíngulo, en ratones infectados con rabia mediante diferentes tipos de inoculación y sus respectivos controles.

No. promedio de neuronas CR + en $1 \mathrm{~mm}$ de corteza

\begin{tabular}{lcc}
\cline { 2 - 3 } Tipo de inoculación & $\begin{array}{c}\text { Corteza } \\
\text { frontal }\end{array}$ & $\begin{array}{c}\text { Corteza del } \\
\text { cíngulo }\end{array}$ \\
\hline Virus "calle" intracerebral & $57 \pm 11$ & $73 \pm 7$ \\
Controles & $61 \pm 8$ & $78 \pm 4$ \\
$(\mathrm{n}=6)$ & $p=0.150$ & $p=0.090$ \\
Virus "calle" intramuscular & $60 \pm 8$ & $76 \pm 6$ \\
Controles & $64 \pm 9$ & $81 \pm 7$ \\
(n=6) & $p=0.240$ & $p=0.120$ \\
Virus "fijo" intramuscular & $58 \pm 6$ & $74 \pm 8$ \\
Controles & $64 \pm 9$ & $81 \pm 7$ \\
(n=6) & $p=0.120$ & $p=0.090$ \\
\hline
\end{tabular}

Cuadro 5. Tamaño (área) de los perfiles somáticos neuronales inmunorreactivos para calretinina $(C R)$ en la corteza frontal y en la corteza del cíngulo de ratones infectados con rabia y sus respectivos controles.

\begin{tabular}{|c|c|c|}
\hline \multirow[b]{2}{*}{ Tipo de inoculación } & \multicolumn{2}{|c|}{$\begin{array}{l}\text { Tamaño de neuronas } \\
C R+\text { en la corteza } \\
\text { Área del soma en } \mu \mathrm{m}^{2}\end{array}$} \\
\hline & $\begin{array}{l}\text { Corteza } \\
\text { frontal }\end{array}$ & $\begin{array}{l}\text { Corteza del } \\
\text { cíngulo }\end{array}$ \\
\hline $\begin{array}{l}\text { Virus "calle" intramuscular } \\
\text { Controles } \\
(n=6){ }^{*}\end{array}$ & $\begin{array}{c}84 \pm 13 \\
86 \pm 15 \\
p=0.409\end{array}$ & $\begin{array}{c}84 \pm 14 \\
87 \pm 13 \\
p=0.290\end{array}$ \\
\hline $\begin{array}{l}\text { Virus "fijo" intramuscular } \\
\text { Controles } \\
(\mathrm{n}=6)^{*}\end{array}$ & $\begin{array}{c}76 \pm 13 \\
85 \pm 14 \\
p=0.197\end{array}$ & $\begin{array}{c}69 \pm 11 \\
88 \pm 12 \\
p=0.030\end{array}$ \\
\hline
\end{tabular}

neuronal fue especialmente notable sobre las células infragranulares en donde, además de la reducción de tamaño, se perdió la inmunorreactividad en los procesos celulares (figura $5 \mathrm{~d}$ ).

Para confirmar el efecto del virus 'fijo' sobre la expresión de $\mathrm{CB}$, se llevó a cabo un segundo experimento con ratones de mayor edad $(6$ a 8 semanas). La primera observación importante fue que se incrementó la inmunorreactividad, especialmente en los controles, lo cual incluye un aumento en el número de células $\mathrm{CB}+$. No obstante, se repitió el efecto de la infección sobre la expresión de CB. Además de reducirse notoriamente la inmunotinción del neuropilo y las células en el material infectado, la disminución del número de perfiles neuronales inmunorreactivos fue igualmente significativa $(p=0,004)$ a la del primer experimento (cuadro 2).

\section{Expresión y distribución de calretinina}

Se observaron neuronas $\mathrm{CR}+$ desde la capa I hasta la capa $\mathrm{VI}$, pero la mayoría se localizaron hacia las capas II-III. Fueron predominantemente células bipolares con somas ovoides o fusiformes cuyo eje principal, así como sus dendritas, se orientaron en sentido perpendicular a la piamadre (figura 6a). Muy cerca de la corteza frontal, en la corteza del cíngulo, fue evidente otra población muy densa de neuronas $\mathrm{CR}+$, muchas de ellas con morfología predominantemente bipolar; por esta razón, se decidió incluirlas en el estudio (figura 6b). En el material control, el diámetro promedio mínimo de los somas, tanto en la corteza frontal como en la corteza del cíngulo $\mathrm{CR}+$, fue de $8,6 \mu \mathrm{m}$ y el máximo de $14,0 \mu \mathrm{m} \quad(\mathrm{n}=480)$.

En el cuadro 4 se resumen los resultados correspondientes al número de neuronas $\mathrm{CR}+$ en una columna de $1 \mathrm{~mm}$ de corteza frontal y $1 \mathrm{~mm}$ de corteza del cíngulo. En el cuadro 5 se anotan los tamaños de los perfiles somáticos $\mathrm{CR}+$ en los diferentes grupos de estudio. Al comparar el número de neuronas que expresaron $\mathrm{CR}$ en la corteza frontal, no se halló diferencia estadísticamente significativa entre los controles y el material infectado por cualquiera de los tipos de inoculación. Resultados estadísticamente similares se obtuvieron en la corteza del cíngulo. Tampoco se encontró efecto significativo de la infección con virus 'calle' sobre el tamaño de los perfiles de los somas neuronales $\mathrm{CR}+$ en la corteza frontal ni en la corteza del cíngulo. Sin embargo, en la infección con virus 'fijo', si bien el efecto sobre el tamaño de los somas en la corteza frontal no fue estadísticamente significativo $(p=0,197)$, sí lo fue sobre el tamaño promedio de los perfiles somáticos de las neuronas $\mathrm{CR}+$ de la corteza del cíngulo $(p=0,030)$. 

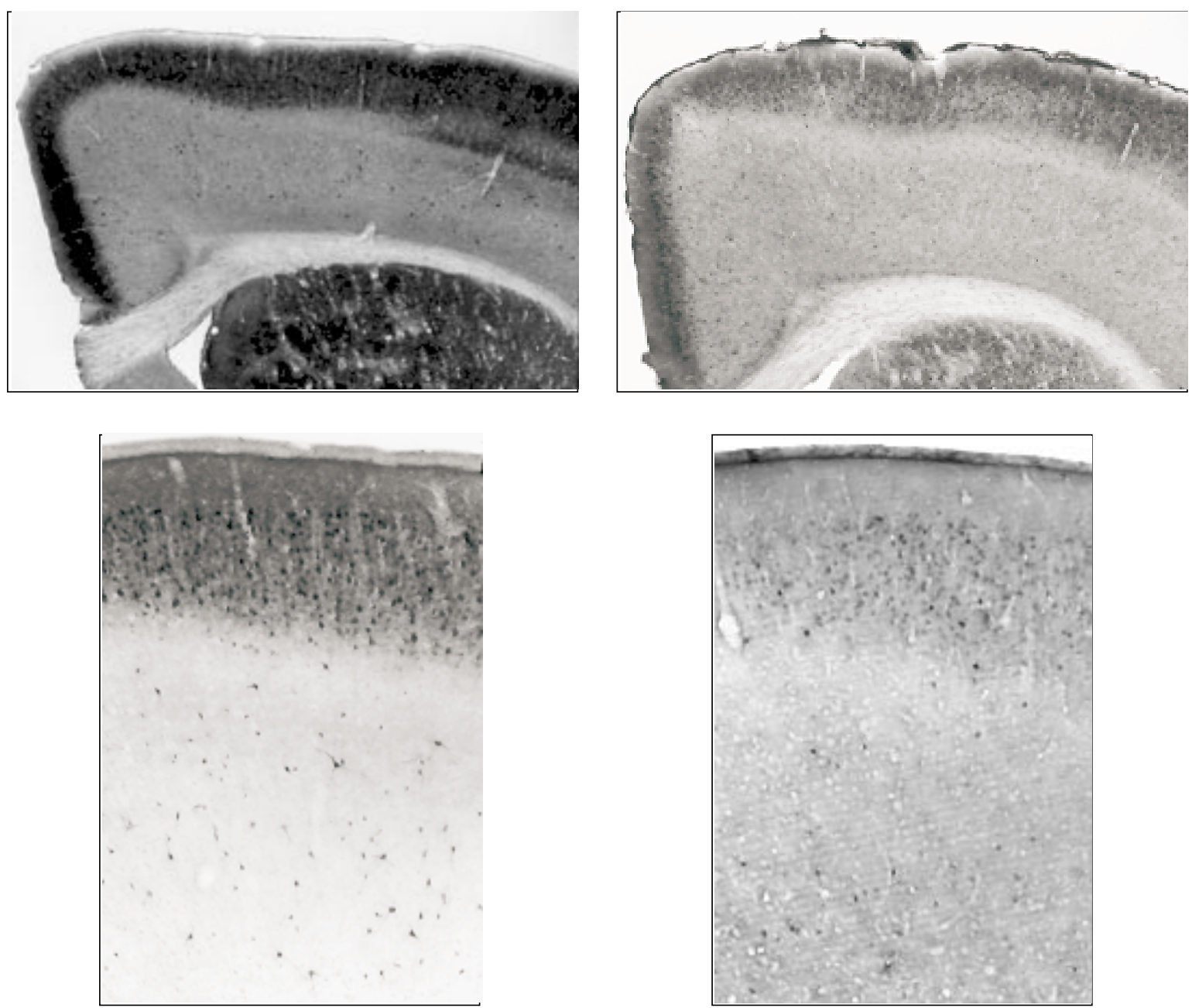

Figura 5. a y b. Imágenes panorámicas de la inmunorreactividad a CB en la corteza frontal del ratón. Ratón normal (a) y ratón infectado con virus "fijo" de la rabia (b). Nótese la pérdida parcial de inmunotinción en el animal infectado. 50X. c y d imágenes en mayor aumento de la inmunorreactividad a CB en la corteza frontal del ratón. Ratón normal (c) y ratón infectado con virus "fijo" de la rabia (d). En este último nótese la pérdida de inmunotinción en el estrato supragranular ( $\uparrow$ ) así como la escasez de neuronas marcadas en el estrato infragranular ( $\downarrow$ ). 125X.

\section{Discusión}

\section{Tipos de virus y vías de inoculación de la rabia}

La inoculación del virus de la rabia en ratones, por vía intracerebral, es el método más utilizado en el laboratorio, según la literatura internacional, debido a que en pocos días los animales manifiestan los síntomas de la enfermedad y mueren. Este procedimiento forma parte del protocolo recomendado para confirmar un diagnóstico de importancia epidemiológica (31). Sin embargo, la inoculación intramuscular corresponde a una ruta de entrada más natural del virus (32) y menos traumática, debido a que se evita el daño adicional al tejido cerebral provocado por la acción mecánica de la inyección a través del cráneo. Cuando el propósito es investigar en profundidad la citopatología del tejido nervioso infectado, la lesión al tejido cerebral que puede provocar la inyección podría interferir, por ejemplo, desencadenando eventos necróticos o apoptósicos que luego serían atribuidos a la actividad del virus. Si, además de 

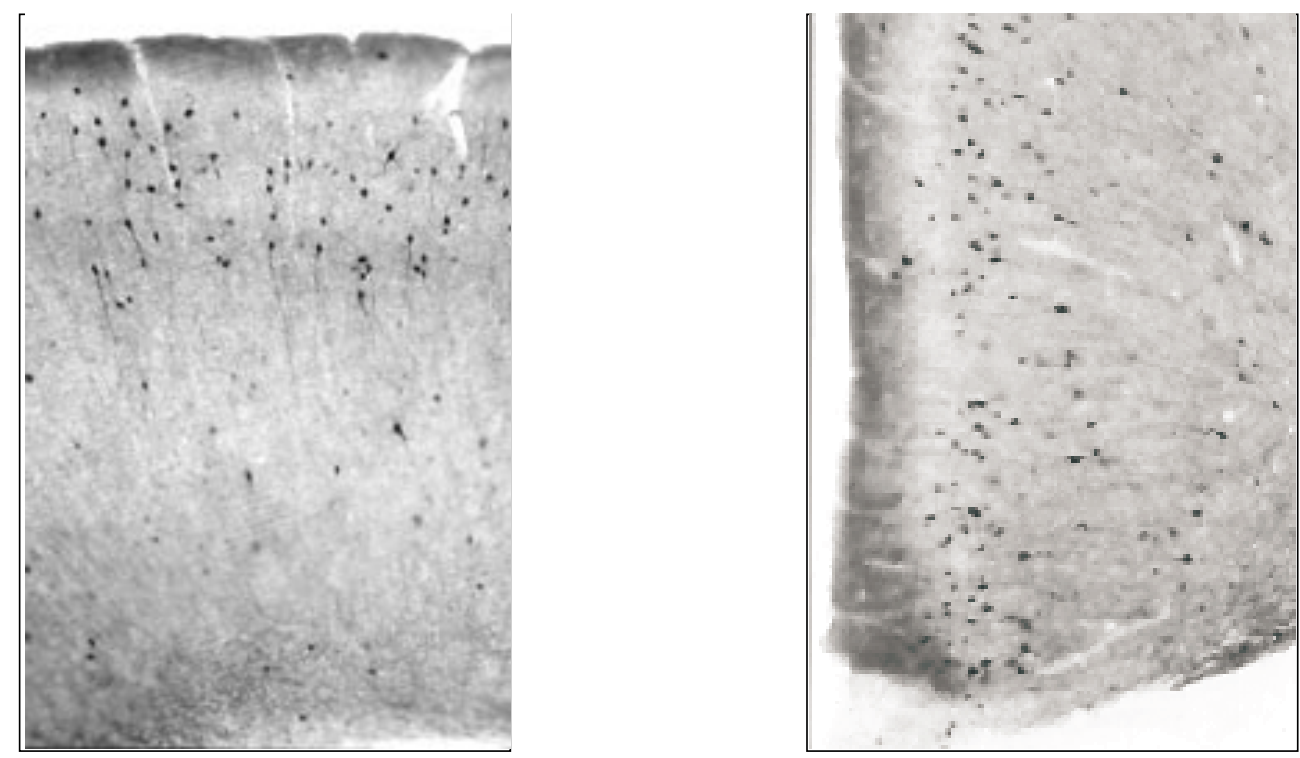

Figura 6. Distribución de las neuronas $\mathrm{CR}+$ en la corteza frontal (a) y corteza del cíngulo (b) del ratón. Nótese en esta última la mayor densidad de células marcadas. a, 125X; b, 160X.

hacer la inoculación por vía periférica, ésta se realiza con virus de origen silvestre o virus 'calle', se reproduce con mayor aproximación el comportamiento natural de la enfermedad. El estudio histológico se realizó con animales enfermos en estado terminal para aumentar la probabilidad de lograr alteraciones estructurales evidentes. Diferentes estudios han demostrado que el mayor efecto de la enfermedad se observa sólo al final, especialmente cuando se han inoculado animales con virus 'calle' o inclusive también en casos de rabia en seres humanos (9).

En el presente trabajo se compararon diferentes vías de inoculación con los dos tipos de virus. Se comprobó el comportamiento diferente de la enfermedad en los animales infectados por cada uno de los métodos y el efecto citopático diferencial entre el virus 'calle' y el virus 'fijo', a través de un método no utilizado anteriormente para el estudio histopatológico de la rabia. Investigaciones anteriores han demostrado grandes diferencias en la patogénesis de cada uno de estos tipos de virus de la rabia (9). El virus 'fijo' produce efectos citopáticos más severos tanto en cultivos celulares como en los animales y la inclusión eosinofílica, o cuerpo de Negri, no es visible en el tejido infectado por este tipo de virus $(14,16,33,34)$.
Además, el fenómeno de la apoptosis neuronal ampliamente documentado en estudios con virus 'fijo' $(11,16)$, apenas se ha informado en un par de casos de infecciones con virus 'calle', uno de ellos experimental (35) y el otro en un paciente enfermo de sida (36).

Inmunorreactividad a $P V, C B$ y $C R$ en el ratón normal

Las neuronas PV+ de la corteza cerebral corresponden a células en cesta y células en candelabro. La mayoría de interneuronas supragranulares $\mathrm{CB}+$ corresponden a células bipenachadas (término originalmente utilizado por Cajal), mientras que las interneuronas infragranulares $\mathrm{CB}+$ son principalmente células de Martinotti y células neurogliaformes. La mayor cantidad de neuronas corticales $\mathrm{CR}+$ son células bipolares y en menor proporción se encuentran algunas células bipenachadas y las células horizontales de Cajal de la capa I $(4,19,20)$.

La distribución de la inmunorreactividad a las tres proteínas (PV, CB y CR) en la corteza frontal de ratón fue, salvo algunas diferencias, muy similar a la conocida en ratas en diferentes zonas de la neocorteza, incluso la corteza frontal $(18,20,37$, 38). Igualmente, es semejante a la distribución 
descrita recientemente en la corteza visual de ratones, aunque en esta última se notó una concentración menor de neuronas $\mathrm{CB}+$ en las capas supragranulares $(39,40)$. Las imágenes publicadas en otro artículo reciente sobre la distribución de CB en la corteza frontal de ratas (41) revelan una menor inmunorreactividad de este marcador en las capas supragranulares comparada con la obtenida en el presente trabajo. También aquí se obtuvo un mayor número de neuronas $\mathrm{CR}+$ comparado con el descrito para la rata en un estudio anterior (18). Esto quizá se debe a diferencias en la técnica inmunohistoquímica.

La mayor inmunorreactividad a $\mathrm{CB}$ en los ratones de 6 a 8 semanas comparada con los de 4 a 6 semanas se explica por el proceso de maduración del sistema nervioso. También se observó un efecto similar en algunas muestras de 6 a 8 semanas que se procesaron para PV y CR. Se conocen casos en otras especies en las cuales la distribución definitiva de las CaBP en el adulto ocurre después de varios meses o algunos años $(18,20)$. La fuerte inmunotinción del neuropilo en las capas supragranulares proviene principalmente de los procesos celulares de las neuronas CB+ de la corteza, especialmente de los haces de axones de las células bipenachadas (41). También contribuyen algunas proyecciones talamocorticales y probablemente aferencias desde los núcleos del rafé $(19,37)$.

En general, aunque se presentan algunas diferencias cuantitativas, los patrones laminares de la distribución cortical de PV, CB y CR en la corteza cerebral de ratón y de rata son semejantes a los de otros mamíferos estudiados, especialmente carnívoros y primates, incluso el hombre $(18,20)$. Esto coincide con la teoría según la cual, en el cerebro de los mamíferos, la estructura de la corteza cerebral conserva un patrón básico uniforme, especialmente entre los órdenes antes mencionados $(3,42)$, a tal grado que el número absoluto de neuronas contado en columnas corticales de la misma anchura es constante en el ratón, la rata, el gato, el mono y el hombre (42). Por tanto, estos roedores son un buen modelo para desarrollar investigación en patología experimental con base en el análisis del comportamiento de la expresión de PV, CB y CR en la corteza cerebral.

\section{Inmunorreactividad a PV en ratones afectados por rabia}

No hubo efecto de la infección sobre el número de neuronas que expresaron PV ni sobre el tamaño de los somas de estas células, con ninguno de los tipos de inoculación. No obstante, el virus de la rabia parece inducir un aumento en la expresión de esta proteína a juzgar por la mayor intensidad de la inmunotinción en todos los casos. Esto facilitó la observación de los terminales axónicos de las células en cesta (anillos de botones sinápticos alrededor de somas de las neuronas piramidales) y de las células axo-axónicas o células en candelabro (cadenas verticales cortas de sinapsis que conectan con el segmento inicial del axón de neuronas piramidales), aunque también se observaron en el material no infectado pero con menor intensidad de inmunotinción. Estas estructuras PV+ han sido ampliamente descritas en primates $(2,19,43)$ pero pocas veces observadas en roedores(37,38). En un artículo reciente sobre PV en la corteza visual del ratón y del hámster, aunque la inmunorreactividad fue intensa, no se observa ni se menciona la presencia de botones sinápticos perisomáticos o terminales de las células axo-axónicas (40).

En la literatura revisada se halló apenas una mención breve sobre el aumento en la intensidad de la inmunorreactividad a PV así como a CB y $C R$ en algunas neuronas corticales en casos de enfermedad de Alzheimer (44). Sin embargo, no hay datos similares en la mayoría de publicaciones revisadas sobre esta patología. Experimentalmente, en ratas, se ha inducido aumento en la inmunorreactividad a PV y CB mediante estímulos eléctricos en diferentes tipos de fibras que conducen al hipocampo $(17,25)$. Se ha propuesto que estos cambios se deben al aumento de la concentración intracelular de la proteína por efecto de una alteración del metabolismo o a cambios en la conformación de la molécula que la harían más reconocible a los anticuerpos (25).

No hay antecedentes sobre el efecto de un virus neurotrópico en la expresión de las proteínas ligadoras de calcio, objeto del presente estudio. 
Una primera hipótesis sería que el virus de la rabia aumenta la expresión del gen que codifica para PV por alguna razón relacionada con su supervivencia. En un estudio reciente, una cepa del virus 'fijo' de la rabia inoculada en ratones provocó la disminución en la expresión del 90\% de los genes evaluados, pero en el 1,4\% (39 genes) aumentó la expresión, incluso en genes involucrados en la regulación del metabolismo celular, síntesis de proteínas y actividad sináptica, todos ellos relacionados con la necesidad del virus de reproducirse y diseminarse a otras células (45).

Una segunda hipótesis estaría relacionada con la función protectora de las células que se atribuye a estas proteínas por su capacidad para regular el calcio intracelular $(17,20,25)$. Una mayor concentración de PV luego de la infección podría ser una respuesta de la neurona a la entrada de iones $\mathrm{Ca}^{++}$en exceso inducida por la actividad del virus. Existe evidencia experimental sobre el efecto del virus de la rabia en el transporte a través de la membrana celular y la expresión de canales iónicos $(11,12,46,47)$. Además, estudios electrofisiológicos han clasificado a las neuronas PV+ como células FS (fast-spiking), esto es, que pueden descargar repetitivamente a altas frecuencias; por tanto, son de gran actividad metabólica, mayor que la de otras neuronas corticales $(37,48,49)$. Esta mayor actividad está asociada con la entrada de iones $\mathrm{Ca}^{++}$a la célula requerida para la liberación del neurotransmisor $(17,48,49)$. La PV regula el incremento del calcio intracelular después de la excitación sináptica lo cual evita el efecto nocivo del exceso de $\mathrm{Ca}^{++}$en la célula presináptica $(48,49)$. La infección por el virus podría desencadenar mayor actividad sináptica con la consiguiente entrada de calcio y, así, disparar la síntesis de proteínas reguladoras de calcio intracelular.

Con estos antecedentes, surge la inquietud acerca de las posibles consecuencias derivadas de la mayor concentración de PV inducida por el virus sobre la función neurológica. Los cambios en la inmunorreactividad a las CaBP pueden indicar alteraciones funcionales en las respectivas neuronas (25). En ratones mutantes PV-/-, la falta de parvoalbúmina transforma sinapsis supresoras en sinapsis facilitadoras (49). La facilitación es el mecanismo por el cual un estímulo produce una liberación de neurotransmisor mucho mayor que un estímulo idéntico aplicado previamente (50). El retorno a la condición normal $(\mathrm{PV}+/+)$ inhibe la facilitación (49). Entonces, se podría pensar que una concentración elevada de PV intracelular, más allá de lo normal, daría lugar a una menor liberación de neurotransmisor (en este caso de GABA) con las consecuencias fisiopatológicas que ello acarrearía.

Inmunorreactividad a $C B$ en ratones afectados por rabia

No hubo diferencias significativas entre animales controles e infectados sobre la expresión de CB cuando se inoculó virus 'calle' por cualquiera de las dos vías ensayadas. Por el contrario, el virus 'fijo' provocó disminución notable de la inmunorreactividad y pérdida del número de células que expresaron el marcador, así como disminución significativa del tamaño de las neuronas $\mathrm{CB}+$. En principio no se puede afirmar que el menor número de perfiles neuronales $\mathrm{CB}+$ corresponda a una pérdida por muerte neuronal. Puede tratarse únicamente de inhibición de la expresión de la proteína aunque la célula siga intacta. Sin embargo, la reducción en el tamaño del soma y las neuritas es un factor indicativo de atrofia y pérdida neuronal $(21,24,44)$.

Cualquiera que sea el caso, la pérdida de CB puede ocasionar efectos graves sobre la función celular y la integración neuronal. La falta de CB en las neuronas puede afectar su homeostasis ante la menor capacidad para regular la entrada de $\mathrm{Ca}^{++}$. Puesto que todas ellas son gabaérgicas, la deficiencia de CB podría dar lugar a trastornos metabólicos en este sistema neurotransmisor.

Recientemente se ha propuesto, con base en estudios previos sobre la localización de canales de calcio en la corteza cerebral, que la alta inmunorreactividad a CB en las capas supragranulares de la corteza frontal estaría relacionada con la presencia de una gran densidad de canales de calcio en las capas superficiales de esta zona cortical. Por tanto, la CB podría estar allí para regular el flujo de calcio (41). El virus 'fijo' de la rabia provoca una fuerte disminución de la inmuno- 
rreactividad supragranular a CB; por lo tanto, afectaría la función de controlar la entrada de calcio en estas capas superficiales.

\section{Inmunorreactividad a $C R$ en ratones afectados por rabia}

Por los resultados aquí presentados, se concluye que hay un efecto leve de la rabia sobre la expresión de $\mathrm{CR}$, apenas significativo estadísticamente en la reducción del tamaño de las neuronas $\mathrm{CR}+$ en la corteza del cíngulo de los animales inoculados con virus 'fijo'. Este marcador neuronal ha sido menos estudiado en neuropatología comparado con $\mathrm{PV}$ y CB, en parte quizá porque su descubrimiento es más reciente. Por otra parte, la CR ofrece alguna dificultad para su detección en la corteza cerebral, mediante la técnica inmunohistoquímica, de acuerdo con la experiencia del presente trabajo y los resultados de investigaciones previas.

En los trabajos publicados sobre histopatología, en los que se evalúa la $C R$, se encuentra que la subpoblación de interneuronas que la expresa parece ser la menos afectada, especialmente en la corteza cerebral. La inmunorreactividad a CR se preserva sin mayores cambios en diferentes áreas de la corteza en la enfermedad de Alzheimer $(26,51)$, la demencia con cuerpos de Lewy (52) y la encefalopatía espongiforme transmisible (53). Igualmente, las neuronas $\mathrm{CR}+$ son resistentes a la degeneración en el estriado de pacientes con la enfermedad de Huntington (54).

En el presente trabajo se comprobó que predomina la forma bipolar entre las neuronas $\mathrm{CR}+$ de la corteza cerebral del ratón. Éstas poseen un cuerpo celular muy pequeño comparado con el de otras interneuronas y se localizan preferencialmente hacia las capas supragranulares (II y III). Estos resultados coinciden con los de otros autores que han trabajado este marcador en diferentes especies y áreas corticales $(20,38,39,55)$.

La aparente vulnerabilidad de las células $\mathrm{CR}+$ en la corteza del cíngulo afectada por el virus 'fijo' de la rabia podría estar relacionada con los efectos de esta enfermedad sobre el sistema autónomo $(8-11,15,16)$. La circunvolución del cíngulo hace parte del sistema límbico y el área de estudio aquí descrita corresponde a la corteza prefrontal medial (áreas 24 y 25) (38). Recientemente se ha hallado evidencia experimental de la participación de estas áreas corticales en los mecanismos del arco reflejo visceral. El área 24 recibe y procesa la información de las aferencias víscerosomáticas mientras que el área 25 envía señales descendentes víscero-motoras (56). Sería importante conocer el papel que desempeñan las interneuronas bipolares de la corteza del cíngulo en estos circuitos y cómo pueden ser alterados por la actividad del virus de la rabia.

En conclusión, como aportes del presente trabajo se destacan los siguientes: 1) contribución al conocimiento de la distribución inmunohistoquímica de las neuronas que expresan las proteínas ligadoras de calcio PV, CB y CR en la corteza frontal del ratón;2) con una metodología no utilizada antes para estudiar la patología de la rabia, se demostró una vez más la diferencia notable entre la histopatología de la rabia inducida por el virus natural (virus 'calle') y la inducida por el virus adaptado en el laboratorio (virus 'fijo'); 3 ) se comprobó que son pocos los cambios sufridos por las inteneuronas inmunorreactivas a PV, CB, y CR, en la corteza cerebral, en el modelo murino de infección por virus silvestre (virus 'calle'). Sin embargo, en futuros estudios se debe establecer el significado funcional que pueda tener el incremento en la concentración de PV inducido por el virus, más aún cuando fue la única alteración común en todos los experimentos, sin importar el tipo de virus utilizado o la vía de inoculación; 4) el efecto del virus 'fijo' sobre la inmunorreactividad a la CB en la corteza frontal y a la CR en la corteza del cíngulo es un aporte al conocimiento que puede adquirir importancia en el futuro. No se puede descartar que las alteraciones en la inmunorreactividad a $C B$ y $C R$ se presenten en infecciones producidas por diferentes cepas de virus 'calle' en sus principales hospederos naturales (carnívoros, quirópteros, primates), pues se sabe que los roedores no lo son. Por otra parte, el hecho de no encontrar mayores efectos de la rabia natural sobre la expresión de las CaBP en la corteza cerebral no significa que esto mismo ocurra en otras áreas del sistema nervioso, tal como se ha demostrado en otras patologías; 5) 
finalmente, el conjunto de resultados aquí obtenidos refuerza la hipótesis sobre la participación del sistema gabaérgico en la fisiopatología de la rabia, en particular por el efecto del virus 'fijo' que induce pérdida de inmunorreactividad a CB en la corteza frontal y disminución del tamaño neuronal $\mathrm{CR}+$ en la corteza del cíngulo, así como por el efecto de los dos tipos de virus, cualquiera que sea su vía de inoculación, sobre la intensidad de inmunotinción a la PV.

\section{Agradecimientos}

Este trabajo fue cofinanciado por el INS y el Fondo de Investigaciones en Salud, Ministerio de SaludColciencias, proyecto 2104-04-11805. El primer autor agradece también a Colciencias el apoyo para realizar el doctorado en la Universidad del Valle (Colombia) y una pasantía en el Instituto de Neurociencias de la Universidad Miguel Hernández (Alicante, España) en el laboratorio del Dr. Alfonso Fairén, a quien desea expresar su gratitud; de este entrenamiento surgió la idea para realizar la presente investigación. También agradece al Dr. Gerzaín Rodríguez (Laboratorio de Patología, INS) director de la tesis doctoral; su apoyo fue fundamental para realizar el doctorado y este trabajo. Ha sido también importante la colaboración de los doctores Gabriel Toro (INS), Facundo Valverde y Javier DeFelipe (Instituto Cajal) y de los Laboratorios de Patología, Virología, Neurociencias y Bioterio del INS. Finalmente, un reconocimiento a Carmen Elena Libreros por su ayuda en la preparación del manuscrito.

\section{Referencias}

1. Fairén A, DeFelipe J, Regidor J. Nonpyramidal neurons: general account. En: Peters A, Jones E, editores. Cerebral cortex. Vol. 1. Cellular components of the cerebral cortex. New York: Plenum Press; 1984. p.201-53.

2. DeFelipe $\mathbf{J}$, Fariñas $\mathbf{I}$. The pyramidal neuron of the cerebral cortex: morphological and chemical characteristics of the synaptic inputs. Prog Neurobiol 1992; 39:563-607.

3. Nieuwenhuys R. The neocortex. An overview of its evolutionary development, structural organization and synaptology. Anat Embryol 1994;190:307-37.

4. DeFelipe J. Cortical interneurons: from Cajal to 2001. Prog Brain Res 2002;136:216-38.
5. Valverde F. Estructura de la corteza cerebral. Organización intrínseca y análisis comparativo. Rev Neurol 2002;34:758-80.

6. Petroff OAC. GABA and glutamate in the human brain. Neuroscientist 2002;8:562-73.

7. De Luka S, Protic S, Vrbaski S. Gamma aminobutyric acid: its function, disorders and their sequelae. Med Pregl 1998;51:319-24.

8. Warrel DA. The clinical picture of rabies in man. Trans R Soc Trop Med Hyg 1976;70:188-95.

9. Tsiang H. Pathophysiology of rabies virus infection of the nervous system. Adv Virus Res 1993;42:375-412.

10. Mrak R, Young L. Rabies encephalitis in humans: pathology, pathogenesis and pathophysiology. J Neuropathol Exp Neurol 1994;53:1-10.

11. Jackson A. Pathogenesis. En: Jackson A, Wunner H, editors. Rabies. San Diego: Academic Press; 2002. p.245-82.

12. Ladogana A, Bouzamondo E, Pocchiari M, Tsiang H. Modification of tritiated gamma amino-butyric acid transport in rabies virus-infected primary cortical cultures. J Gen Virol 1994;75:623-7.

13. Khizhniakova T, Promyslov M, Gorshunova L. The influence of rabies immunization of gammaaminobutyric acid metabolism in the brains of animals. Biull Eksp Biol Med 1976;81:184-5.

14. Rodríguez G, Sarmiento L. Rabia: el cuerpo de Negri. Biomédica 1999;19:196-7.

15. Toro G, Raad J. Rabia. En: Toro G, Hernández CA, Raad J, editores. Instituto Nacional de Salud 1917-1997: una historia, un compromiso. Bogotá: Instituto Nacional de Salud; 1997. p.309-18.

16. Iwasaki Y, Tobita M. Pathology. En: Jackson A, Wunner $\mathrm{H}$, editores. Rabies. San Diego: Academic Press; 2002. p.283-307.

17. Baimbridge K, Celio M, Rogers J. Calcium-binding proteins in the nervous system. Trends Neurosci 1992; 15:303-30.

18. Andressen C, Blumcke I, Celio M. Calcium-binding proteins: selective markers of nerve cells. Cell Tissue Res 1993;271:181-208.

19. DeFelipe J. Types of neurons, synaptic connections and chemical characteristics of cells immunoreactive for calbindin-D28K, parvalbumin and calretin in the neocortex. J Chem Neuroanat 1997;14:1-19.

20. Hof P, Glezer I, Condé F, Flagg R, Rubin M, Nimchinsky E, Vogt Weisenhorn D. Cellular distribution of the calcium-binding proteins parvalbumin, calbindin and calretinin in the neocortex of mammals: phylogenetic and developmental patterns. J Chem Neuroanat 1999;16:77-116. 
21. Guentchev M, Hainfellner J, Trabattoni G, Budka H. Distribution of parvalbumin-immunoreactive neurons in brain correlates with hippocampal and temporal cortical pathology in Creutzfeldt-Jakob disease. J Neuropathol Exp Neurol 1997;56:1119-24.

22. Beasley C, Reynolds G. Parvalbumin-immunoreactive neurons are reduced in the prefrontal cortex of schizophrenics. Schizophr Res 1997;24:349-55.

23. DeFelipe J. Chandelier cells and epilepsy. Brain 1999; 122:1807-22.

24. Masliah E, Ge N, Achim C, Wiley A. Differential vulnerability of calbindin-immunoreactive neurons in HIV encephalitis. J Neuropathol Exp Neurol 1995;54: 350-7.

25. Heizmann C, Braun K. Changes in $\mathrm{Ca}^{2+}$-binding proteins in human neurodegenerative disorders. Trends Neurosci 1992;15:259-64.

26. Leuba G, Kraftsik R, Saini K. Quantitative distribution of parvalbumin, calretinin and calbindin D-28k immunoreactive neurons in the visual cortex of normal and Alzheimer cases. Exp Neurol 1998;152:278-91.

27. Páez A, Nuñez C, García C, Boshell J. Epidemiología molecular de epizootias de rabia en Colombia, 19942002: evidencia de rabia humana y canina asociada a quirópteros. Biomédica 2003;23:19-30.

28. Valverde F. Golgi atlas of the postnatal mouse brain. Viena: Springer-Verlag; 1998. p.48-51.

29. Sarmiento L, Rodríguez G, de Serna C, Boshell J, Orozco L. Detection of rabies virus antigens in tissue: immunoenzymatic method. Patologia 1999;37:7-10.

30. Schefler WC. Bioestadistica. México: Fondo Educativo Interamericano; 1981. p. 218-21.

31. Trimarchi C, Smith J. Diagnostic evaluation. En: Jackson A, Wunner H, editors. Rabies. San Diego: Academic Press; 2002. p.307-49.

32. Jackson A. Biological basis of rabies virus neuro-virulence in mice: comparative pathogenesis study using the immunoperoxidase technique. J Virol 1991;65: 53740.

33. Miyamoto K, Matsumoto S. Comparative studies between pathogenesis of street and fixed rabies infection. J Exp Med 1967;125:447-56.

34. Rodríguez G. Microscopía electrónica de la infección viral. Bogotá: Instituto Nacional de Salud; 1983. p.119-39.

35. Ubol S, Kasisith J. Reactivation of Need-2, a developmentally down-regulated apoptotic gene, in apoptosis induced by a street strain of rabies virus. J Med Microbiol 2000;49:1043-6.

36. Adle-Biassette $\mathbf{H}$, Bourhy $\mathbf{H}$, Gisselbrecht $\mathbf{M}$, Chrétien $\mathrm{F}$, Wingertsmann $\mathrm{L}$, Baudrimont $\mathrm{M}$ et al. Rabies encephalitis in a patient with AIDS: a clinicopathological study. Acta Neuropathol (Berl) 1996; 92:415-20.
37. Celio M. Calbindin D-28k and parvalbumin in the rat nervous system. Neuroscience 1990;35:375-475.

38. Gabbott P, Dickie B, Vaid R, Headlam A, Bacon S. Local-circuit neurones in the medial prefrontal cortex (areas 25,32 and 24b) in the rat: morphology and quantitative dsitribution. J Comp Neurol 1997;377:465-99.

39. Park HJ, Kong JH, Kang YS, Park WM, Jeong SA, Park So, et al. The distribution and morphology of calbindin and calretinin-immunoreactive neurons in the visual cortex of mouse. Mol Cells 2002;14:143-9.

40. Park HJ, Hong SK, Kong JH, Jeon CJ. Localization of calcium binding protein parvalbumin immunoreactive neurons in mouse and hamster visual cortex. Mol Cells 1999;9:542-7.

41. Sun XZ, Takahashi S, Cui C, Inoue M, Fukui Y. Distribution of calbindin immunoreactive neurons in rat primary motor cortex. J Med Invest 2002;49:35-9.

42. Rockel A, Hiorns R, Powell T. The basic uniformity in structure of the neocortex. Brain 1980;103:221-44.

43. Akil M, Lewis D. Differential distribution of parvalbumin-immunoreactive pericellular clusters of terminal boutons in developing and adult monkey neocortex. Exp Neurol 1992;115:239-49.

44. Mikkonen M, Alafuzoff I, Tapiola T, Soininen H, Miettinen R. Subfield and layer-specific changes in parvalbumin, calretinin and calbindin immunoreactivity in the entorhinal cortex in Alzheimer's disease. Neuroscience 1999;92:515-32.

45. Prosniak M, Hooper C, Dietzschold B, Koprowski H. Effect of rabies virus infection on gene expression in mouse brain. Proc Natl Acad Sci USA 2001;98:275863.

46. Iwata M, Komori S, Unno T, Minamoto N, Ohashi H. Modification of membrane currents in mouse neuroblastoma cells following infection with rabies virus. $\mathrm{Br}$ J Pharmacol 1999;126:1691-8.

47. Iwata M, Unno T, Minamoto N, Ohashi H, Komori S. Rabies virus infection prevents the modulation by a2-adrenoceptors, but not muscarinic receptors, of $\mathrm{Ca}^{++}$ channels in NG108-15 cells. Eur J Pharmacol 2000;404: 79-88.

48. Kawaguchi Y, Kubota Y. Correlation of physiological subgroupings of nonpyramidal cells with parvalbumin and calbinding immunoreactive neurons in layer $\mathrm{V}$ of rat frontal cortex. J Neurophysiol 1993;70:387-96.

49. Caillard O, Moreno H, Schwaller B, Llano I, Celio $\mathbf{M}$, Marty A. Role of the calcium-binding protein parvalbumin in short-term synaptic plasticity. Proc Natl Acad Sci USA 2000;97:13372-7.

50. Ceña V. Comunicación interneuronal. Tipos de sinapsis. En: Delgado JM, Ferrús A, Mora F, Rubia F, editores. Manual de neurociencia. Madrid: Editorial Síntesis; 1998. p.183-99. 
51. Sampson V, Morrison J, Vickers J. The cellular basis for the relative resistance of parvalbumin and calretinin immunoreactive neocortical neurons to the pathology of Alzheimer's disease. Exp Neurol 1997;145: 295-302.

52. Gómez-Tortosa E, Sanders J, Newell K, Hyman B. Cortical neurons expressing calcium binding proteins are spared in dementia with Lewy bodies. Acta Neuropathol (Berl) 2001;101:36-42.

53. Guentchev M, Groschup M, Kordek R, Liberski P, Budka H. Severe, early and selective loss of a subpopulation of GABAergic inhibitory neurons in experimental transmissible spongiform encephalopathies. Brain Pathol 1998;8:615-23.
54. Cicchetti F, Prensa L, Wu Y, Parent A. Chemical anatomy of striatal interneurons in normal individuals and in patients with Huntington's disease. Brain Res Rev 2000;34:80-101.

55. del Río M, DeFelipe J. Synaptic connections of calretinin immunoreactive neurons in the human neocortex. J Neurosci 1997;17:5143-54.

56. Baklavadzhian 0 , Nersesian L, Avetisian E, Avetisian I, Arshakian A, Bagdasarian $\mathrm{K}$, et al. The neuronal organization of the limbic-(cingulo)-visceral reflex arc. Usp Fiziol Nauk 2000;31:11-23. 